\title{
Reflexões didático-pedagógicas acerca do ensino do esporte no processo de formação de professores de Educação Física
}

\author{
Ricardo Rezer*
}

\begin{abstract}
Resumo: O objetivo deste texto se apresenta no sentido de refletir acerca de pressupostos orientadores para uma abordagem crítica do esporte no processo de formação inicial em educação física. Para tal, são apresentadas algumas experiências de aula desenvolvidas no componente curricular "Metodologia, teoria e prática do futebol e futsal" (Unochapecó). Tais experiências podem ser compreendidas como um laboratório de experiências pedagógicas, a fim de apresentar elementos para uma abordagem crítica no trato com o esporte no ensino superior. Finalmente, o texto apresenta alguns apontamentos "suleadores" para uma abordagem crítica dos esportes na formação inicial em EF.

Palavras-chave: Educação superior. Esporte. Prática Profissional.
\end{abstract}

\section{CONSIDERAÇõES INICIAIS}

O ensino do esporte no processo de formação de professores de EF (Educação Física) é um tema complexo e vasto a ser pesquisado. $\mathrm{O}$ que um futuro professor de EF precisa aprender sobre esporte para que possa se apresentar como um professor com fundamentação suficiente para sustentar um processo de intervenção? Trata-se de uma questão importante que merece maior atenção da comunidade acadêmica e que, inicialmente, motivou o enfrentamento das questões apresentadas neste texto.

Nessa direção, sem querer "responder" a este dilema, ao mesmo tempo em que pretendo "não me furtar" a enfrentá-lo, objetivo com este texto desenvolver uma reflexão acerca de elementos didáticopedagógicos para uma abordagem crítica do esporte no processo de formação inicial em EF. Para tal, inicialmente, apresento uma reflexão

* Professor da Universidade Comunitária Regional de Chapecó (UNOCHAPECO). Doutorando em Educação Física (PPGEF/UFSC). Florianópolis, SC, Brasil. E-mail: rrezer@hotmail.com 
sobre estudos que vêm abordando o ensino dos esportes na formação inicial em EF. Em um segundo momento, apresento reflexões sobre elementos que podem contribuir para uma abordagem crítica do esporte na formação de professores de EF, a partir de algumas experiências pedagógicas desenvolvidas no contexto específico da Universidade Comunitária Regional de Chapecó (UNOCHAPECÓ). Finalmente, apresento reflexões didático-pedagógicas para uma abordagem crítica do esporte na formação de professores de EF.

Portanto, este texto se propõe a participar do movimento (ainda recente) de decodificar para os processos de formação inicial em EF, aquilo que muitas obras (KUNZ, 1994, SOARES et al, 1992, entre outras) vêm propondo para a EF escolar. Desta forma, a relevância deste artigo se apresenta na direção de contribuir com a prática pedagógica no ensino superior, mais especificamente, o trato com o esporte neste âmbito.

Parto do princípio de que dilemas do trato pedagógico nos diferentes espaços de intervenção no campo da EF precisam ser considerados na formação inicial, visto que parece relevante associar possíveis transformações em diferentes contextos de intervenção com experiências oriundas do processo de formação.

\section{ENSINO dO ESPORTE NA FORMAÇÃO INICIAL EM EF}

Já se produziu diferentes abordagens sobre o trato com o esporte no contexto escolar ao longo dos últimos anos que, em tese, promoveram significativas contribuições no âmbito da EF escolar brasileira nos últimos 20 anos. Estas abordagens, cada uma a seu modo, apresentamse como importante contribuição para a EF brasileira. (HILDEBRANDT; LAGING, 1986; SOARES et al, 1992; KUNZ, 1994; ASSIS DE OLIVEIRA, 2001, entre outras).

Por outro lado, percebe-se uma preocupação contemporânea bastante acentuada com outras abordagens relativas ao campo da EF: políticas públicas, lazer, saúde, corpo, entre outras. Mas com relação a elementos didático-pedagógicos, que possam contribuir de forma significativa com o exercício da docência, especificamente, vem se

Movimento, Porto Alegre, v. 16, n. 01, p. 271-292, janeiro/março de 2010. 
percebendo uma insuficiência de produções com a densidade necessária para tal desafio. ${ }^{1}$ Dessa forma, é possível perceber um hiato no que se refere ao período de lançamentos de certas obras, como as apresentadas anteriormente, e a contemporaneidade da EF. Se, por um lado, há uma vasta produção da EF na contemporaneidade, ${ }^{2}$ vivemos ainda um período de grande angústia sobre "o-que-fazer" nos contextos de intervenção. Esta questão remete ao desafio de enfrentar o hiato entre a produção acadêmica e a prática pedagógica da EF.

No entanto, se é possível perceber certa carência de trabalhos contemporâneos mais densos voltados para a prática pedagógica na EF escolar, mais evidente ainda é a carência de propostas críticas para o trato com o esporte no contexto do ensino superior, no processo de formação inicial de professores de EF. Ao que parece, a ênfase da intervenção neste âmbito continua voltada para o ensino de determinados elementos específicos do esporte, a partir do que Kunz (1994) e Bracht (1992) referem-se como uma abordagem restrita do esporte e da EF.

Em certa medida, é possível inferir que estudos voltados para o trato com o esporte no contexto escolar vêm servindo de referência para subsidiar o trabalho desenvolvido na prática pedagógica pertinente ao ensino superior. Partindo destas considerações iniciais, pretendo abordar a temática proposta neste artigo a partir de duas hipóteses: a) a prática pedagógica referente ao ensino dos esportes no ensino superior não pode ser uma adaptação das proposições voltadas para a escola mas sim ser tratada como um contexto com necessidades e características próprias, com procedimentos específicos e, portanto, ainda com insuficiência de produção teórica de cunho didático-pedagógico; b) a necessidade de socializar de maneira mais concreta experiências pedagógicas no trato com o esporte no ensino superior, apontando avanços e limitações para este contexto.

Tais questões não poderão ser enfrentadas sem pensar na possibilidade de contribuir na formação de novos professores que tenham

\footnotetext{
1 Ver mais em Rezer e Fensterseifer, 2008.

2 Somente no Congresso Brasileiro de Ciências do Esporte (CONBRACE), realizado na cidade de Recife (PE), em 2007, foram lançadas 34 obras.

Movimento, Porto Alegre, v. 16, n. 01, p. 271-292, janeiro/março de 2010.
} 
oportunidades de vivenciar "alternativas" (com todo o cuidado que esta palavra sugere) pedagógicas em seu processo de formação inicial.

Por outro lado, é possível perceber um movimento (ainda tímido) na direção de avançar com proposições que se posicionem de maneira crítica frente a esta lacuna na produção do conhecimento (o trato com o esporte no ensino superior). Desta forma, alguns estudos vêm sendo desenvolvidos nos últimos anos, na direção de ampliar este debate. Trabalhos como os de Oliveira (1989); Molina Neto (1995); Daólio (1998); Ferreira (1998); González (1999, 2004, 2007); Pires e Neves (2002); Nascimento (2004), entre outros, vêm se preocupando em questionar as abordagens simplificadas do ensino do esporte no contexto do ensino superior em EF.

Porém, é possível perceber que esta temática se manifesta há pouco tempo nos periódicos da área (o trabalho de Oliveira, por exemplo, data de 1989), o que permite pensar que a temática referente ao trato com o esporte no ensino superior ainda carece de maiores estudos. Assim sendo, tais referências permitem pensar sobre a necessidade de ampliar o debate acerca das proposições pedagógicas voltadas para o trato com o esporte neste âmbito.

Tal necessidade fica mais evidenciada no trabalho de Oliveira (1989), que apresenta um estudo sobre as disciplinas esportivas do curso de EF da Universidade Estadual de Maringá (UEM) e conclui que os procedimentos didático-pedagógicos que organizam as aulas reproduzem o aprendizado do esporte institucionalizado, tido como função fundamental destas disciplinas. Esse mesmo estudo apresenta evidências afirmando que os procedimentos didático-pedagógicos neste âmbito caracterizam-se basicamente por serem de tipo fechado e sem espaço de decisão para os alunos, restando a eles estarem presentes e obedecerem ao professor. Conforme conclusões do estudo, pode-se inferir que isso resulta em uma prática pedagógica, por parte dos egressos, reprodutiva, submissa, ingênua e com fim em si mesma.

Por um lado, este artigo datado de 1989 permite considerar que vários avanços ocorreram nos últimos 20 anos. Por outro lado, a carência de estudos que permitam considerar que as conclusões de Oliveira são elementos do passado possibilita inferir que muitas intervenções

Movimento, Porto Alegre, v. 16, n. 01, p. 271-292, janeiro/março de 2010. 
pedagógicas no âmbito do ensino superior ainda se apresentam desta maneira.

É possível afirmar que, mesmo com as frequentes alterações na formação inicial em EF ocorrida nos últimos anos, conforme Nascimento (2004), as práticas pedagógicas estruturadas para o ensino dos esportes ainda se sustentam por uma abordagem tradicional do ensino. Concordando com González (2004), as disciplinas esportivas não mudaram quanto ao tratamento do conteúdo. A aparente redução do número e carga horária de disciplinas esportivas nos currículos dos cursos de EF passa mais por uma questão de quantidade de disciplinas que por uma transformação qualitativa no entendimento do fenômeno esportivo no campo do ensino superior em EF.

Ao que parece, a mudança de forma não necessariamente vem promovendo mudança de conteúdo. Relacionando esta discussão com dois trabalhos de Vago $(1996,2003)$, o autor apresenta uma necessidade contemporânea para o campo da EF: pensar em uma cultura escolar esportiva. Partindo disso, compreendendo a universidade como um contexto de ensino formal, tal qual a escola (obviamente com outras demandas, necessidades, expectativas e exigências), é possível inferir que o contexto universitário carece de uma cultura acadêmica para o ensino do esporte.

O que ensinar para possibilitar ao futuro professor condições para o ensino do esporte, como um sujeito autônomo que em sua intervenção pedagógica atua em primeira pessoa, trata-se de uma preocupação que deve interessar ao docente no ensino superior. Lembrando González (1999), não podemos pensar que ministrar aulas na EF escolar ou no esporte infantil é (simplesmente) reproduzir aquilo que se "vê" nas aulas das disciplinas esportivas na universidade, pois os objetivos, sujeitos e circunstâncias são completamente diferentes. Juntamente aos futuros professores, participamos (na condição de docentes), de um processo de construção do conhecimento necessário para que a futura intervenção pedagógica não se reduza à simples reprodução, desenvolvendo as competências necessárias para que tenham possibilidades de oportunizar aos seus alunos a reconstrução inteligente, competente e contextualizada (se possível, prazerosa), em aulas críticas, de conteúdos pertinentes à cultura corporal de movimento.

Movimento, Porto Alegre, v. 16, n. 01, p. 271-292, janeiro/março de 2010. 
Considerando, então, que nas aulas da graduação encontram-se professores em processo de formação inicial, tais encaminhamentos se manifestam como elementos importantes para a constituição de um outro paradigma de ensino no contexto da formação inicial em EF. Portanto, as proposições aqui expressas se apresentam no sentido de contribuir com um movimento, ainda recente, que pretende ampliar as responsabilidades pedagógicas do processo de formação inicial no campo da EF.

\section{UMA ABORDAGEM DO ESPORTE NA FORMAÇÃO DE PROFESSORES DEEF: OCASO DOS "FUTEBÓIS"}

Partindo desta contextualização inicial, serão apresentadas a seguir algumas experiências pedagógicas desenvolvidas em algumas aulas da disciplina de Teoria, prática e metodologia do futebol e do futsal. ${ }^{3}$ Tais experiências se apresentam no sentido de subsidiar o pano de fundo que permitirá apresentar reflexões didático-pedagógicas para uma abordagem crítica do esporte na formação inicial em EF.

Este componente curricular apresenta algumas possibilidades interessantes, entre outras: a) turmas mistas (na região oeste de Santa Catarina há diversos cursos de EF com turmas divididas em masculinas e femininas); b) estudantes ainda em fase inicial no processo de formação e, em tese, motivados para a aprendizagem; c) o futebol e o futsal abordados através da concepção de "futebóis", assumida ao longo das aulas, que será abordada mais a frente.

Por outro lado, é possível perceber algumas limitações: a) alguns alunos ainda muito imaturos (ingressando precocemente na universidade); b) imbuídos de expectativas muito voltadas para a aquisição de competências de natureza estritamente técnica; c) carga horária diminuta para o componente curricular (04 créditos); d) pequeno embasamento teórico que permita aos estudantes compreender melhor as

\footnotetext{
${ }^{3}$ Disciplina do curso de Licenciatura em EF da UNOCHAPECÓ, 04 créditos do $2^{\circ}$ período da matriz curricular, e tem por objetivo "Analisar, refletir e compreender o futebol de campo e o futsal em suas diferentes dimensões, relacionando-os com o contexto escolar, compreendendo questões pedagógicas do processo ensino/aprendizagem, bem como suas relações sociais, políticas e culturais na sociedade contemporânea".
}

Movimento, Porto Alegre, v. 16, n. 01, p. 271-292, janeiro/março de 2010. 
proposições desenvolvidas (por exemplo, carência de uma compreensão mais clara e crítica sobre o esporte).

Após esta contextualização preliminar, serão apresentadas, em três atos, algumas experiências pedagógicas desenvolvidas em aula, neste componente curricular.

\section{1 $11^{\circ}$ Ato: definindo os conteúdos do Plano de Ensino}

Inicialmente, foi necessário esclarecer aos estudantes a concepção de "futebóis" que seria assumida ao longo das aulas. Se, por um lado, o futebol e o futsal são modalidades esportivas específicas, por outro, há a necessidade de uma mediação pedagógica para o ensino de seus elementos no contexto escolar e também no processo de formação de professores, pois não se trata apenas de um conjunto de técnicas, de sistemas, de regras etc. Na concepção aqui assumida, "futebóis" apresenta-se como uma possibilidade que permite à EF tratar pedagogicamente o futebol, o futsal, o futebol suíço, entre outros, a partir de uma compreensão crítica que lhe confira o status de conhecimento da cultura corporal de movimento, digno de ser ensinado, sendo tratado como um objeto de estudo do processo de formação inicial e, por consequência, como objeto de estudo nos processos de intervenção, sem desconsiderar de maneira alguma seus elementos específicos.

Conforme Damo (2007), "futebóis" não é simplesmente um neologismo de ocasião. O dicionário Aurélio contém, desde seu lançamento, o plural para o termo futebol. Porém, "futebóis" é um termo usado com pouca frequência. No entanto, o reconhecimento da diversidade deste fenômeno é manifesto na linguagem cotidiana, como: futebol de várzea, de salão, de botão, de praia, futsal, soçaite, futevôlei, totó, "pelada", "racha", entre outros. ${ }^{4}$

\footnotetext{
${ }^{4}$ Vejamos a seguinte situação: um grupo de crianças, jogando no momento do recreio, em uma quadra de futsal de cimento, com uma bola de futebol de campo, com sete para cada lado. Como definir isso: futsal, futebol ou futebol sete? Jogo ou esporte? A abordagem aqui proposta permite maior amplitude, ao considerar essa diversidade como possível de ser abordada em espaços de intervenção da EF. Isso permite considerar que as relações entre esporte e jogo se encontram muito imbricadas na EF escolar, em um diálogo constante. Tal paradoxo merece ser levado em consideração no trato com o esporte no âmbito escolar, pois se entende que esporte e jogo se encontram em uma zona de fronteira de difícil demarcação, onde um, invariavelmente, invade o terreno do outro.
}

Movimento, Porto Alegre, v. 16, n. 01, p. 271-292, janeiro/março de 2010. 
Considero que a definição dos conteúdos passa pelo prisma de percepção do conhecimento a ser ensinado. Assim, ampliar as possibilidades de intervenção do docente começa pela ampliação da percepção da complexidade do objeto em questão ou, como se refere Fensterseifer (2007): 5 "o mundo é da largura do meu conhecer".

Nesse sentido, a partir de algumas referências ${ }^{6}$, foram sistematizadas quatro formas de pensar os "futebóis", na perspectiva de "reconstruir/decodificar" a abordagem de tais conteúdos no âmbito acadêmico: Jogos Populares/de Rua (pelada, reba,...); Jogos Esportivos (futebol, futsal, futebol suíço,...); Jogos de Salão (botão, pebolim, dedogol,...) e Jogos Eletrônicos (FIFA,....). ${ }^{7}$

Isso contribuiu na constituição dos conteúdos a serem estudados, tendo como referência o objetivo do componente curricular e os conhecimentos considerados necessários para um professor de EF ser conhecedor do tema "Futebóis" e, por consequência, possuir competência para ensinar. Cabe lembrar que o recorte dos conhecimentos considerados necessários para o ensino é de responsabilidade do professor e não dos estudantes. Principalmente porque, geralmente, é visível a preocupação dos estudantes com as especificidades técnicas. Desta forma, é necessário que o professor apresente argumentos que permitam uma ampliação da percepção dos estudantes para trazer à tona a complexidade de ensinar a ensinar, tendo como objeto o tema "futebóis".

Conforme amadurecimento pautado por diversas tentativas (acertos e erros), apresento a seguir as escolhas que orientaram o desenvolvimento do componente curricular, subdivididas em três blocos, que avançam em relação ao conteúdo específico, sem desmerecê-lo, mas atribuindo-lhe um papel menos central (como expresso, assumo a escolha de uma abordagem de conteúdos generalista, que trata por cobertura o conteúdo abordado), conforme a seguir:

\footnotetext{
5 . Comunicação Oral. ljuí, 29/08/2007.

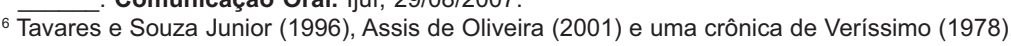
"Futebol de rua".

${ }^{7}$ Tal sistematização permite ampliar a compreensão das manifestações dos "futebóis", partindo de uma diversidade que não pode ser desprezada. Como exemplo, em geral, os jogos eletrônicos estão mais presentes no cotidiano dos estudantes do que no dos professores.
}

Movimento, Porto Alegre, v. 16, n. 01, p. 271-292, janeiro/março de 2010. 


\begin{tabular}{|c|l|}
\hline Bloco I & $\begin{array}{l}\text { Ampliando o entendimento para além do futebol/futsal: os "futebóis" percebidos como } \\
\text { fenômeno cultural; a estruturação e organização de grupos através da prática dos "futebóis"; } \\
\text { os "futebóis" como jogos populares/de rua ("pelada", "racha", goleirinha",...); regras como } \\
\text { construções coletivas. }\end{array}$ \\
\hline Bloco II & $\begin{array}{l}\text { Os "futebóis": o jogo de bola com os pés; jogos de bola com as mãos (e o goleiro?); } \\
\text { metodologia e prática dos pequenos e grandes jogos; contrução coletiva de jogos de } \\
\text { "futebóis"; futebol de várzea; jogos de salão (futebol de botão, totó/fla-flu,...); jogos } \\
\text { eletrônicos. }\end{array}$ \\
\hline Bloco III & $\begin{array}{l}\text { "Afunilando" o conhecimento específico (o jogo fica sério): jogos esportivos; futebol de } \\
\text { campo; futsal, futebol sete; regras específicas; relação técnica-tática; fundamentos técnico- } \\
\text { táticos (jogadores de linha e goleiro); sistemas de jogo (evolução histórica, formatações e } \\
\text { setores); questões específicas: defesa, ataque, contra-ataque, funções e cobertura. }\end{array}$ \\
\hline
\end{tabular}

Quadro 1 - Conteúdos básicos para uma abordagem dos "futebóis".

Fonte: Plano de ensino de Teoria, Prática e Metodologia do Futebol e do Futsal.

Não é alvo deste artigo discutir pormenorizadamente sobre cada bloco. No entanto, é possível perceber que tais encaminhamentos se apresentam como aberturas de possibilidades de intervenção ao longo do processo, configurando o trato com os "futebóis" a partir de três dimensões: histórico-social (Unidade I), didático-pedagógica (Unidade II) e técnico-instrumental (Unidade III), que são mais específicas em cada bloco, mas que se entrelaçam no decorrer do processo, abrindo caminho para diversas experiências, tais como o recorte a seguir.

\section{$3.22^{\circ}$ ATO: ABORDANDO OS JOGOS POPULARES DE "FUTEBÓIS" COMO TEMA DE AULA}

Um dos recortes a ser abordado nas aulas seria referente ao tema: "Jogos Populares/de Rua". Desta forma, procurou-se evidenciar a preocupação em "olhar" por cima do muro da escola (ou da universidade). O conhecimento pertinente ao trato com o esporte no ensino superior precisa ser alargado, visto que o conhecimento que está presente neste contexto não se resume a "experiência-em-si", pois o acadêmico precisa dominar mais elementos que aqueles necessários à simples prática do esporte em questão, entendendo as aulas como espaços de laboratório pedagógico, de legítimo exercício de experiências de docência.

Para tal, é possível considerar princípios importantes a serem desenvolvidos com os alunos no contexto do ensino superior: compreender o papel do professor - "dominar" elementos didático-pedagógicos e metodológicos que constituem os procedimentos de desenvolvimento das aulas; dominar conhecimentos específicos (técnica,

Movimento, Porto Alegre, v. 16, n. 01, p. 271-292, janeiro/março de 2010. 
tática, regras, sistemas etc.), bem como compreender a importância de orientar a intervenção por um projeto curricular que permita maior autoridade pedagógica no decorrer das aulas propostas. ${ }^{8}$

Desta forma, a questão expressa anteriormente, "o-que-fazer", foi revisitada a partir de um processo de discussão. Mas, antes de explorar este "o-que-fazer", a abordagem inicial se pautou por uma exploração e um resgate das memórias dos estudantes, do que brincavam em sua infância, quais os "jogos de bola" vividos, enfim, suas experiências anteriores, a partir do chamado "Resgate de Jogos Populares de Futebóis". Tais experiências possibilitaram a vivência em aula de memórias individuais que se manifestaram no coletivo, em um processo de socialização de conhecimentos anteriores ao ingresso na universidade.

Desta forma, este $2^{\circ}$ Ato pretendeu subsidiar possibilidades para estudar os jogos populares/de rua neste âmbito, como recorte/ tema de aula. O próximo ato irá se deter de forma mais ampliada nesta proposição.

\section{3 $3^{\circ}$ Ato: "Construção Coletiva de Jogos" - experienciando O ENSINO DO ENSINO DOS "FUTEBÓIS"}

Partindo dos encaminhamentos adotados anteriormente, foi possível construir algumas experiências concretas para o ensino dos "futebóis" neste contexto específico. A base teórica para tal empreitada se apresentou a partir do recorte de alguns trabalhos, no sentido de fundamentar as proposições desenvolvidas pelos alunos e pelo professor. ${ }^{9}$

Houve uma abordagem destas referências, no sentido de refletir com os estudantes acerca das possibilidades e limitações de tais pro-

\footnotetext{
${ }^{8}$ Ao dominar tais elementos, o futuro professor não precisa, necessariamente, ser dependente dos manuais de exercícios, jogos ou "atividades" ou de cursos de "capacitação", pois sua prática pedagógica se pautará por uma possibilidade de autonomia que não se esgota em qualquer livro de "1000 exercícios de...".

${ }^{9}$ Os estudantes se organizaram em grupos que precisaram estudar sete trabalhos: Hildebrandt e Laging (1986) - Capítulo I e Experiências Práticas; Soares et al (1992) - Os tópicos Jogo e Futebol Kunz (1994) - O tópico Reflexões a Partir de Experiências Concretas; Molina Neto (1995) - Texto na íntegra; Vago (1996) Texto na íntegra; Rezer (1997) - Tópico Construção Coletiva de Jogos; Rezer e Saad (2005) - O Capítulo III.

Movimento, Porto Alegre, v. 16, n. 01, p. 271-292, janeiro/março de 2010.
} 
postas. ${ }^{10}$ Partindo do estudo destas referências em pequenos grupos e de um enunciado, os estudantes, baseados nas experiências de aula, nas leituras realizadas e nas experiencias vivenciadas fora da universidade, precisariam articular com um grupo de colegas, um jogo de bola com os pés. Os procedimentos ocorreram conforme a seguir:

\section{$1^{\circ}$ MOMENTO: TEMATIZAÇÃO - CONSTRUÇÃO/RECONSTRUÇÃO CONJUNTA} DO CONHECIMENTO:

Partindo das referências estudadas e do enunciado, os grupos deveriam apresentar e discutir suas experiências passadas com jogos de "futebóis", apresentando sugestões a fim de chegar a um consenso para possibilidades de prática, ou seja, o que iriam jogar na aula.

\section{$2^{\circ}$ MOMENTO: EXPERIMENTANDO O JOGO (VIVÊNCIAS/EXPERIÊNCIAS DO CONHECIMENTO CONSTRUÍDO/RECONSTRUÍDO):}

Cada grupo "jogou seu jogo", legitimando uma ideia organizada em conjunto, caracterizando a utilização de uma proposta criada ou recriada pelo próprio grupo. Neste momento, os alunos deveriam experimentar o jogo, em um momento de prática e sistematização básica das regras e dos procedimentos mínimos para desenvolvimento do jogo (o que pode e o que não pode ser feito).

\section{$3^{\circ}$ MOMENTO: ORGANIZAÇÃO E SISTEMATIZAÇÃO DAS EXPERIÊNCIAS (SOCIALIZAÇÃO DO CONHECIMENTO):}

Os alunos conversaram no grande grupo, "contando" como era seu jogo, regras e objetivos principais, e o grande grupo apresentou críticas e sugestões. Isto caracteriza um trabalho de sistematização por parte do grupo que apresentava e de análise e avaliação pelos ouvintes, exigindo para tal procedimentos didático-pedagógicos e metodológicos para ser compreendido. A partir disso, o jogo poderia ser modificado e, em certos casos, redimensionado em sua estrutura.

\footnotetext{
${ }^{10}$ Cada grupo de alunos teve uma semana para se apropriar destas referências. Após este período, 04 aulas (uma tarde) foram destinadas para a discussão acerca do referencial de sustentação proposto. Para o desenvolvimento deste $3^{\circ}$ Ato, especificamente, foram necessárias outras 04 aulas, desenvolvidas ao longo de uma tarde.

Movimento, Porto Alegre, v. 16, n. 01, p. 271-292, janeiro/março de 2010.
} 
$4^{\circ}$ MOMENTO: UM CIRCUITO DE JOGOS:

Após a socialização dos jogos construídos por todos os grupos, estava montado um circuito de jogos de "futebóis", arquitetado pelo coletivo. Partindo disso, cada grupo iria praticar o jogo desenvolvido pelos outros grupos, em forma de um circuito, caracterizando a socialização do conhecimento desenvolvido. Em síntese, cada grupo desenvolveu um jogo de "futebóis" e aprendeu com os demais colegas diversos outros jogos.

50 MOMENTO: DISCUSSÃO NO "GRANDE GRUPO": O QUE SE PODE PENSAR ACERCA DESTA PROPOSTA? QUAIS SEUS LIMITES E POSSIBILIDADES?

Este momento permitiu que cada grupo comentasse sobre suas dificuldades, erros, acertos e problemas encontrados no desenrolar da aula, bem como críticas e sugestões. Assim, professor e alunos tiveram oportunidade de analisar o trabalho desenvolvido.

\section{$6^{\circ}$ MOMENTO: SISTEMATIZAÇÃO E FUNDAMENTAÇÃO DO CONHECIMENTO PRODUZIDO:}

Finalizando, cada grupo buscou subsidiar sua proposta com os trabalhos estudados anteriormente, articulando conhecimento acadêmico e o conhecimento produzido na aula. Neste momento, era necessário escrever uma síntese do processo, contendo uma sistematização do jogo construído (estrutura: regras, objetivos, materiais e procedimentos necessários para sua prática) e a fundamentação didáticopedagógica considerada mais adequada para contextualizar este processo no ensino fundamental (como ensinar). ${ }^{11}$

A opção por utilizar o jogo como conteúdo básico desta proposta de aula se deu pelo fato de que é possível argumentar que as relações entre esporte e jogo se encontram muito imbricadas, em um diálogo constante, entre algo que pode ser controlado e algo que escapa ao controle de quem joga. Tal paradoxo merece ser levado em conside-

\footnotetext{
${ }^{11}$ Como exemplo, um dos grupos relacionou a abordagem de Soares et al (1992) sobre futebol (p. 71) e sobre jogo (p. 65), fundamentando melhor a proposta apresentada em aula e a compreensão deste exercício de docência, entendendo que a "teoria", como eles se referiam, permite uma ampliação na capacidade de operar com os problemas do mundo.

Movimento, Porto Alegre, v. 16, n. 01, p. 271-292, janeiro/março de 2010.
} 
ração no trato com o esporte no ensino superior, visto que em breve estes estudantes passarão a ser docentes e precisam de maior clareza nesta discussão. ${ }^{12}$ Entende-se que esporte e jogo se encontram em uma zona de fronteira de difícil demarcação, onde um, invariavelmente, invade o terreno do outro. ${ }^{13}$

Observou-se que o resgate de jogos populares de "futebóis" originou vários outros jogos. Isso corrobora as ideias apresentadas por Vago (1996), na perspectiva de constituir uma cultura esportiva escolar. O esforço deste artigo, então, é contribuir com o movimento de pensar e propor perspectivas para o processo de formação inicial de professores de EF, na perspectiva de contribuir com a construção de uma nova cultura acadêmica para o ensino do esporte neste âmbito.

Talvez esta seja uma boa possibilidade a ser construída no processo de formação de professores de EF, reafirmando a necessidade de articular conhecimento empírico e conhecimento acadêmico, experiências vividas e reflexões sobre a prática, evidenciando a complexidade da docência. ${ }^{14}$

No $3^{\circ}$ Ato, diversos conteúdos propostos no plano de ensino se faziam presentes: regras como construções coletivas; a estruturação e organização de grupos através da prática do futebol; metodologia e prática dos pequenos e grandes jogos; construção coletiva de jogos de "futebóis"; jogos populares/de rua; fundamentos técnico-táticos (jogadores de linha e goleiro), entre outros. Isso representa afirmar a importância de abordar nas aulas os conteúdos propostos no planejamento, bem como permite perceber com maior clareza que estes conhecimentos não são afastados uns dos outros.

No que se refere aos procedimentos didático-pedagógicos, os estudantes listaram alguns procedimentos importantes para o exer-

\footnotetext{
12 Tal clareza precisa ser construída no decorrer do processo de formação inicial, levando em consideração a importância de outros componentes curriculares nesse processo.

${ }^{13}$ Nessa direção, Fensterseifer (2006) se refere à ambiguidade do fenômeno esportivo, afirmando que na contemporaneidade, jogo e esporte parecem viver em uma eterna disputa. Luta entre um esforço objetivador e algo que escapa a uma total objetivação. Partindo disso, observa-se a importância de abordar jogo e esporte em experiências pedagógicas na EF como fenômenos que se afastam e se aproximam, em um diálogo constante.

${ }^{14}$ Partindo destas experiências, abre-se a possibilidade de tematizar experiências com dança, com exercícios ginásticos, entre outros, de forma crítica e significativa.

Movimento, Porto Alegre, v. 16, n. 01, p. 271-292, janeiro/março de 2010.
} 
cício da docência: fala clara, pausada e firme; as pessoas aprendem de diferentes formas $;{ }^{15}$ há elementos que variam, mas alguns são constantes no jogo (todos têm regras e objetivos, são necessárias orientações sobre "como jogar", e todos se desenvolvem em determinado espaço e tempo); concluíram que torna-se interessante iniciar a explicação com uma síntese da ideia geral do jogo, para logo após especificar detalhes, partindo de perguntas do grande grupo; perceber que também se aprende jogando; que as paradas estratégicas ao longo do jogo, em um primeiro momento, são importantes para sedimentar a compreensão dos estudantes; trazer para discussão no âmbito das aulas elementos que se apresentarem ao longo do jogo (situações de violência, honestidade, ética, entre outros); explorar possibilidades de sugestão/participação dos estudantes; permitir que os grupos discutam entre si, a fim de decidirem determinados procedimentos no coletivo, que novas formas de jogar possam ser incorporadas no processo, entre outros.

Entretanto, o mais importante foi considerar a necessidade do estudo, da fundamentação teórica para o exercício da docência. Esta talvez seja uma importante contribuição deste processo. Da mesma forma, os estudantes perceberam a importância de abrir espaço para a vivência lúdica nas aulas, o que significa, como princípio, marcar no próprio corpo experiências vivenciadas nas aulas de EF.

No andamento das aulas, pode-se perceber que para cada ação desenvolvida pelos alunos, era preciso avaliar em certos momentos suas consequências, de acordo com suas regras e objetivos acordados no coletivo. Lembrando Arendt (2005), é preciso estar atento para não oportunizar a 'tirania do grupo', que pode assumir o encaminhamento das 'propostas', se as condições assim o permitirem. Esta proposta de aula abre espaço para esta contradição, visto a sobreposição de alguns alunos sobre outros (os que possuem mais experiência, maior domínio do tema etc.).

Talvez seja possível avançar nesta questão a partir da teoria do agir comunicativo de Habermas (2003). Em outro estudo (REZER,

${ }^{15}$ Por exemplo, mesclar explicação verbal, gestos e esquemas desenhados com giz no chão, pode contribuir no processo de compreensão.

Movimento, Porto Alegre, v. 16, n. 01, p. 271-292, janeiro/março de 2010. 
2006), a partir de pressupostos de Habermas, compreendo o diálogo como espaço de exposição e discussão para fundamentação das pretensões de validade, a partir da problematização, onde entendo ser possível constituir elementos significativos a partir de acordos internos, que podem representar maior legitimidade nos contextos onde se concretizam. Desta forma, a linguagem manifesta-se como sendo fundamental, e a possibilidade de constituir (novos) acordos pode representar de forma concreta perspectivas reais de contribuição no processo de emancipação e esclarecimento. Nesse sentido, as proposições estudadas em aula podem constituir pilares para a constituição da cidadania, onde as relações de poder, dentro de uma lógica a ser construída, possam ser ressignificadas a partir do diálogo.

Finalizando, é possível considerar que propostas nesta direção talvez possam permitir uma abordagem crítica e participativa por parte dos estudantes, onde eles se sintam como professores e professoras (em processo de formação inicial) que estudam, que jogam, que pensam sobre sua intervenção, na perspectiva de melhor compreender e lidar com a complexidade da docência.

\section{REFLEXõES DIDÁTICO-PEDAGÓGICAS PARA UMA ABORDAGEM CRÍTICA DOS ESPORTES NA FORMAÇÃO INICIAL EM EF}

As contradições e ambiguidades que geralmente emergem de propostas como esta se manifestam como um indicativo inquestionável da complexidade que o ensino superior apresenta. A construção deste texto não se deu de forma diferente. Não se trata de apresentar experiências para serem "aplicadas" em outros contextos mas sim ampliar o debate acerca desta temática, a partir de referências desenvolvidas em espaços específicos.

Questionar e apresentar propostas para a prática pedagógica no ensino superior permite refletir com futuros professores acerca de suas responsabilidades pedagógicas no exercício da docência em outros contextos. Isso pode proporcionar subsídios para práticas transformadoras (novamente, com todo cuidado que tal expressão exige), partindo de "exercícios" pedagógicos desenvolvidos no processo de

Movimento, Porto Alegre, v. 16, n. 01, p. 271-292, janeiro/março de 2010. 
formação. Por isso a necessidade de novos estudos que se debrucem com maior rigor às questões levantadas neste texto, no sentido de transpor para a universidade aquilo que muitas obras propõem para a escola. Pensar de que forma os professores do ensino superior, que trabalham diretamente com "modalidades esportivas", vêm se aproximando destas preocupações trata-se de um desafio contemporâneo.

Nesta direção, é necessário articular o comprometimento das Instituições de Ensino Superior (IES) com as questões aqui levantadas, pois superar a concepção hegemônica de esporte, ainda presente nos contextos de formação profissional, é condição sine qua non para esta superação em outros âmbitos. Obviamente, não se trata de simples relação de causa e efeito, mas de pensar que um novo paradigma para o ensino dos esportes no ensino superior pode promover significativos desdobramentos em outros âmbitos.

Do contrário, como pensar na possibilidade de "transformar" a prática pedagógica em diferentes contextos se não pensarmos nestas transformações também no contexto do ensino superior? O quadro a seguir pode explicitar melhor as inferências apresentadas anteriormente, apresentando sinteticamente elementos constituintes para uma abordagem crítica, a partir de uma abordagem hegemônica, referente ao trato com o esporte no ensino superior:

\begin{tabular}{|l|l|}
\hline \multicolumn{1}{|c|}{ Abordagem Hegemônica } & \multicolumn{1}{c|}{ Abordagem Crítica } \\
\hline $\begin{array}{l}\text { Aula centrada no professor e nas especificidades } \\
\text { técnico-táticas. }\end{array}$ & $\begin{array}{l}\text { Aula compartilhada, compreendida como uma possibilidade de } \\
\text { exercício docente, a partir da complexidade de conteúdos } \\
\text { presentes neste contexto, sem abrir mão da responsabilidade } \\
\text { pedagógica do professor. }\end{array}$ \\
\hline Aula como lugar do A-luno (do latim, "não luz"). & Aula como lugar do professor em processo de formação inicial. \\
\hline Aula como espaço para repassar conteúdos. & $\begin{array}{l}\text { Aula compreendida como laboratório pedagógico, de } \\
\text { experiências de docência. }\end{array}$ \\
\hline $\begin{array}{l}\text { Aula como local para o ensino de jogos, } \\
\text { "atividades", "exercícios educativos" etc. }\end{array}$ & $\begin{array}{l}\text { Compreender a aula como um espaço de aquisição de saberes } \\
\text { da docência, onde o mais importante se manifesta no sentido } \\
\text { de compreender as concepções que fundamentam as práticas. }\end{array}$ \\
\hline Jogar na aula (praticar esportes). & $\begin{array}{l}\text { Aprender a pensar sobre o jogar sem, necessariamente, deixar } \\
\text { de jogar (praticando o exercício da docência). }\end{array}$ \\
\hline
\end{tabular}

Quadro 2 - Abordagem hegemônica e crítica para o ensino do esporte no ensino superior.

Fonte: Rezer, 2008.

Todo quadro pode se tornar uma armadilha, devido a seu aparente reducionismo maniqueísta, pois parece ter a pretensão de encaixotar

Movimento, Porto Alegre, v. 16, n. 01, p. 271-292, janeiro/março de 2010. 
a realidade em pequenas gavetas. Porém, a partir dele é possível pensar em possibilidades concretas de transformar as relações apresentadas, contribuindo com um possível (re)significar do trato com o esporte no âmbito acadêmico.

Tais elementos podem contribuir com possibilidades de se construírem, ao longo do tempo, importantes propostas de formação para o ensino superior. Os argumentos apresentados ao longo do texto permitem pensar sobre possibilidades de ampliar este debate para outros componentes curriculares, que apresentam outro arcabouço de conhecimentos pertinente ao ensino superior em EF (ginástica, dança, entre outros).

Dessa forma, as reflexões desenvolvidas neste texto se apresentam como possibilidades para pensar sobre, o que, na velocidade destes tempos difíceis, trata-se de elemento quase revolucionário. As considerações críticas realizadas neste texto não pretendem "resolver" problemas conjunturais construídos na trajetória histórica da EF, muito menos substituir os sujeitos na produção de possíveis soluções (REZER; FENSTERSEIFER; 2008). Obstante a isso, o processo de formação de professores de EF precisa ampliar a compreensão de esporte como um fenômeno cultural, onde elementos oriundos do mundo do trabalho, do jogo, entre outros, precisam ser levados em consideração, a fim de resgatar a sua complexidade, ampliando a dimensão de compreensão desta manifestação cultural tão presente na modernidade, resgatando responsabilidades do ensino superior neste cenário.

\section{ConsideraçõES FINAIS}

Os componentes curriculares que compõem o mosaico do processo de formação inicial precisam construir um processo de articulação entre si. O desafio de diminuir as barreiras entre os diferentes conhecimentos que constituem este âmbito se apresenta como condição sine qua non para um processo de formação que permita aos futuros professores referências positivas e competentes para a complexa profissão docente.

Nessa direção, abrir espaços para esta discussão com os estudantes (conforme aqui proposto), mas também entre o grupo de profes-

Movimento, Porto Alegre, v. 16, n. 01, p. 271-292, janeiro/março de 2010. 
sores e entre a comunidade acadêmica, pode contribuir com novos rumos na construção de um novo paradigma para o exercício da docência no ensino superior e promover possíveis desdobramentos em outros âmbitos. A socialização de propostas construídas em contextos específicos, tais como as referências apresentadas neste texto, pode contribuir com novas tomadas de decisão e novas investidas neste campo.

O campo dos esportes no ensino superior é um terreno de trânsito difícil para novas formas de pensar, pois possui uma tradição muito sedimentada (geralmente sustentada na tradição do esporte e não na tradição do ensino superior). O paradigma hegemônico da docência neste âmbito já vem carregado de estereótipos, de tradição, onde o conhecimento específico passa a ser um elemento muito presente nestes espaços.

Na tentativa de ampliar esta perspectiva, os conteúdos propostos no $1^{\circ}$ Ato pretendem alargar, em certa medida, a dimensão da abordagem dos conhecimentos pertinentes ao exercício da docência, no caso deste texto, pertinentes ao ensino do esporte, contribuindo para que se perceba como sendo possível a proposição de modificações tanto na forma como no conteúdo.

Cabe lembrar que o recorte do conhecimento considerado mais adequado, de maior relevância, em qualquer componente curricular, é sempre uma dura mas decisiva etapa, que compete ao professor realizar. Esta não é uma tarefa dos estudantes. Porém, eles podem se sentir sujeitos neste processo e, por consequência, participar de forma mais concreta de sua própria formação, discutindo e aprendendo como o professor desenvolve esta difícil empreitada. Assim, o processo de construção curricular precisa ser exercitado pelos futuros professores em diferentes componentes curriculares, pois isso se aprende fazendo, errando, fazendo de novo, estudando sobre, entre outros elementos necessários nessa complexa função da docência.

Da mesma forma, faz-se necessário desafiar os estudantes para que aprendam sobre seu trabalho, experimentando, exercitando a docência no cotidiano, colocando-se no lugar do professor, deslocando o epicentro do processo formativo do estudante, da cômoda situação de "aluno", para a de um professor em processo de formação inicial.

Movimento, Porto Alegre, v. 16, n. 01, p. 271-292, janeiro/março de 2010. 
Lembrando Adorno (1995), o talento não se encontra previamente configurado nos homens, mas depende do desafio a que cada um é submetido. Assim sendo, podemos pensar em "conferir talento" (ADORNO, p.170) aos estudantes em seu processo de formação inicial, desafiando-os a sair da cômoda situação de "aluno" para uma situação de compreender os desafios que a docência exige.

Obviamente, outros elementos que não foram considerados neste breve recorte, devido às limitações de espaço, fazem-se necessários neste âmbito de discussão (a avaliação, por exemplo). Certamente, não podemos correr o risco de pensar que a problemática apresentada pode ser superada com "modelos alternativos" de aula. Há muito mais em jogo do que isso, e outros elementos, tais como políticas públicas, as responsabilidades dos cursos, dos centros, dos departamentos e das IES precisam ser referendadas. ${ }^{16}$ Porém, o papel do professor ainda é muito importante neste processo e a solução dos problemas apresentados depende, em certa medida, dos sujeitos envolvidos.

A produção teórica sobre o ensino dos esportes no processo de formação inicial em EF ainda é muito recente. Obstante a estes limites, "cruzar os braços" parece não ser a melhor saída. Novos estudos parecem se constituir como uma importante possibilidade para avançar neste processo, na expectativa de pensar os sujeitos dos cenários de formação, tanto professores como estudantes, como intelectuais da docência. Isso pode contribuir de maneira crítica no processo de formação de futuros docentes, contribuindo com o movimento de pensar o trato com o esporte no ensino superior de maneira mais profunda e crítica.

${ }^{16} \mathrm{O}$ entorno, como se referem Rezer e Fensterseifer, 2008.

Movimento, Porto Alegre, v. 16, n. 01, p. 271-292, janeiro/março de 2010. 
Notes for the deal with sport in physical education teachers' formation

Abstract: This text aims to analyze conceptions that guide a critical approach of the sport in the process of initial formation in physical education. In order to do so, some experiences of classes developed in the curricular component "Methodology, theory and practice of soccer and indoor soccer" (Unochapecó) are presented. These experiences may be understood as lab of pedagogical experiences, in order to present elements for a critical approach in the deal with sport in university courses. Finally, the text has some guide elements to a critical approach of sports in the initial formation in physical education.

Keywords: Higher education. Sports. Professional practice.

\begin{tabular}{|l|}
\hline Apontamentos para trato con el deporte en la \\
formación de profesores de Educaión Física \\
Resumen: El propósito de este texto se presenta para \\
reflexionar sobre los supuestos rectores un enfoque \\
crítico para el deporte en el proceso de formación inicial \\
en educación física. Con este fin, son algunas expe- \\
riencias de aula plan de estudios desarrollado en el \\
componente "metodología, la teoría y la práctica de fútbol \\
y fútbol sala" (Unochapecó). Estas experiencias pueden \\
ser entendidas como un laboratorio para la experiencia \\
educativa, a presentar pruebas de un enfoque crítico \\
en relación con el deporte en la educación superior. Por \\
último, el texto algunas indicaciones "suleadores" para \\
un enfoque crítico de los deportes en la formación inicial \\
en EF. \\
Palabras clave: Educación superior. Deportes. \\
Práctica profesional.
\end{tabular}

\section{REFERÊNCIAS}

ADORNO, T. W. Educação e emancipação. In: Rio de Janeiro: Paz e Terra, 1995.

ARENDT, H. A crise na educação. In: Paulo: Perspectiva, 2005.

Entre o passado e o futuro. São

ASSIS DE OLIVEIRA, S. A reinvenção do esporte: possibilidades da prática pedagógica. Campinas: Autores Associados, 2001.

Movimento, Porto Alegre, v. 16, n. 01, p. 271-292, janeiro/março de 2010. 
BRACHT, V. Educação Física e aprendizagem social. Porto Alegre: Magister, 1992.

DAMO, A. S. Senso de jogo. Esporte e sociedade. Revista Digital, Rio de Janeiro, n. 1, nov.2005/fev.2006. Disponível em: <http://www.lazer.eefd.ufrj.br/espsoc/>. Acesso: $1^{\circ}$. set. 2007.

DAOLIO, J. Fenômeno social esporte na formação profissional em educação física. Revista da Educação Física/UEM; Maringá, v.9, n.1, p.11-115, 1998.

FENSTERSEIFER, P. E. Esporte na contemporaneidade: uma experiência de fronteira. In: REZER, R. (Org.). O fenômeno esportivo: ensaios crítico reflexivos... Chapecó: Argos, 2006.

FERREIRA, M. G. Metodologia de ensino do basquetebol no curso de formação de professores de educação física: um relato de experiência. Pensar a prática, Goiânia, n.1, p.107-124, 1998

GONZALEZ, F. J. As disciplinas esportivas na formação superior: o que aprender e ensinar? Revista Brasileira de Ciências do Esporte, Florianópolis, v.21, n.1, p.585-592, 1999.

O estudo do esporte na formação superior em Educação Física: construindo novos horizontes. Movimento, Porto Alegre, v.10, n.1, p.213-229, jan./abr. 2004.

Potencialidades e limites de uma proposta alternativa de estudo do esporte na formação superior em Educação Física: olhares de professores e acadêmicos. In: CONGRESSO BRASILEIRO DE CIEENCIAS DO ESPORTE, 15., CONGRESSO INTERNACIONAL DE CIÊNCIAS DO ESPORTE, 2., Recife, 2007. Anais... Recife, 2007.

HABERMAS, J. Teoría de la acción comunicativa, II: crítica de la razón funcionalista. 4. ed. Santafé de Bogotá: Taurus, 2003.

HILDEBRANDT, R.; LAGING, R. Concepções abertas no ensino da Educação Física. Rio de Janeiro: Ao Livro Técnico, 1986.

KUNZ, E. Transformação diatico-pedagógica do esporte. ljuí: UNIJUÍ, 1994.

MOLINA NETO, V. Uma experiência de ensino do futebol no currículo de licenciatura em Educação Física. Movimento, Porto Alegre, v.2 n.2, p. 29-37, 1995.

NASCIMENTO, J. V. Metodologias de ensino dos esportes: avanços teóricos e implicações práticas. Revista Portuguesa de Ciências do Desporto, Porto, v. 4, n. 2, 2004.

OLIVEIRA, A. A. B. Análise critica do currículo das disciplinas práticas do curso de educação física da universidade estadual de Maringá. Revista da Educação Física/ UEM, Maringá, v.0, n.1, 1989.

PIRES, G. L.; NEVES, A. O trato com o conhecimento do esporte na formação em educação física: possibilidades para sua transformação didática. In: KUNZ, E. (Org.). Didática da Educação Física 2. Ijuí: UNIJUI, 2002.

Movimento, Porto Alegre, v. 16, n. 01, p. 271-292, janeiro/março de 2010. 
REZER, R. A construção conjunta em aulas de Educação Física: uma análise sobre esta possibilidade. Monografia (Conclusão de Curso) - Universidade Federal de Santa Maria, Santa Maria, 1997.

O fenômeno esportivo: ponderações acerca das contradições do paradigma da 'iniciação'... In: REZER, R. (Org.). O fenômeno esportivo: ensaios crítico reflexivos... Chapecó: Argos, 2006.

Apontamentos para o trato com o esporte na formação de professores de Educação Física... Chapecó, 2008. Mimeo.

REZER, R.; SAAD, M. A. Futebol e futsal: possibilidades e limitações da prática pedagógica em escolinhas. Chapecó: Argos, 2005.

REZER, R.; FENSTERSEIFER, P. E. Docência em Educação Física: reflexões acerca de sua complexidade... Pensar a Prática, Goiânia, v. 11, n. 3, 2008.

SOARES, C. L. et al. Metodologia do ensino de educação física. São Paulo: Cortez, 1992

TAVARES, M.; SOUZA JÚNIOR, M. O jogo como conteúdo de ensino para a prática pedagógica da educação física na escola. Corporis, Recife, v. 1, n. 1, jul./dez. 1996.

VAGO, T. M. O "esporte na escola" e o "esporte da escola": da negação radical para uma relação de tensão permanente - um diálogo com Valter Bracht. Movimento, Porto Alegre, v.3, n. 5, 1996

A Educação Física na cultura escolar: discutindo caminhos para a intervenção e a pesquisa. In: BRACHT, V.; CRISORIO, R. (Org.) A Educação Física no Brasil e na Argentina: identidade, desafios e perspectivas. Campinas: Autores Associados, 2003.

VERISSIMO, L. F. Futebol de Rua. In: O Rei do rock. Porto Alegre: Globo, 1978.

Movimento, Porto Alegre, v. 16, n. 01, p. 271-292, janeiro/março de 2010. 